\title{
English Teacher Education: The Need for a New Perspective
}

\author{
Celia Florén Serrano \\ Universidad de Zaragoza
}

\begin{abstract}
The paper explores the drawbacks that may arise from an excessive emphasis on either teacher education or teacher training in the syllabus of the future English language teacher. Then it analyses the present limitations in the teaching practice within the E.U. del Profesorado de E.G.B. and how some of the existing problems might be overcome.
\end{abstract}

When we design the syllabus for future English language teachers there are some problems which must be faced inexorably and to which there are no clear-cut solutions. Widdowson's dichotomy between teacher training and teacher education does not help us much. It is obvious that we cannot opt only for training, as preparation for «the achievement of a range of outcomes which are specified in advance» (62) is not advisable in a field where evolution flourishes, because, as Widdowson puts it, «this involves the acquisition of goal-oriented behaviour which is more or less formulaic in character and whose capacity for accommodation to novelty is, therefore, very limited» (62). Education, however, seems more adequate, for it focuses «not on the application of ready-made problem-solving techniques but on the critical appraisal of the relationship between problem and solution as a matter of continuum inquiry and of adaptable practice» (Widdowson 62). So it would seem advisable to back what is considered a «holistic approach» to teacher education such as Larson-Freeman advocates, instead of siding with Fanselow and his «competency-based approach.»

Nevertheless, we cannot avoid including a part of the syllabus oriented to provide students with some training, because «critical appraisal» without the acquisition of some skills and techniques is not enough to face a classroom of English learners, and in English teaching there are a number of situations which can be predicted. The knowledge of skills and techniques linked to the carrying out of certain tasks necessary for the performance of the job of teaching will help the new teacher when he begins his teaching career, and compensate for his lack of any real teaching experience. A competent teacher falls back on his stock of experience where repeated situations form a predictable pattern.

It would seem that skill-acquisition is necessary for the young teacher in order to balance his lack of experience. This might be one reason for postponing some aspects 
of teacher education until future in-service training. This is a somewhat risky decision to take, for we cannot equate experience in actual teaching with the acquisition of the skills considered necessary for teaching, nor can education, viewed as «critical appraisal,» be left for a time when the teacher has become set in certain teaching habits which he is not equipped to evaluate critically.

So most syllabus designers opt for a compromise and try to find a balance between the education or holistic approach and the training or competency-based approach. This is what Martha $\mathrm{C}$. Pennington proposes as a conceptual bridge between the two extremes, which she calls «professional teacher preparation» and which has «as goals the development of an extensive repertoire of classroom skills and the judgment to apply these skills as needed» (134).

Initial training or education must be as extensive as possible and it is undoubtedly influenced by the tendencies of the moment. Afterwards it can be assumed that most teachers will then develop their professional activity for a long period of time; in the meanwhile approaches to teaching may change, and actual teaching conditions or social context can also vary. Of course pre-service training does not have to be considered as final and unique, as nowadays opportunities for in-service training are increasing, for it is viewed as a necessity. Nevertheless, initial education cannot count on future retraining to cope with deficiencies acquired at the beginning. In a changing world, where tendencies in theories and practice are not considered definite in any way it is to be hoped that young teachers will be able to face changes with a flexible and critical attitude.

So, when we teach methodology we must, on the one hand, face an ever growing programme, while on the other try to encourage in our teachers-to-be a flexible attitude with regard to the different needs, situations and approaches that the future almost certainly holds in store. The present moment with its emergent LOGSE is a good example of what I am saying, as the new law on education implies an important change in teaching.

Another challenging choice which faces the syllabus designer involves finding the right balance between theory and practice. Initial training or education requires some instruction on theoretical subjects, which the trainees must obtain as students. At the same time part of what they need is not theoretical and must be obtained as skills, and in a more participatory way. All this can be introduced under the general heading of «methodology.» As Richards puts it:

In second language teaching, teacher education programs typically include a knowledge base, drawn from linguistics and language learning theory, and a practical component, based on language teaching methodology and opportunity for practice teaching. (3)

It is often impossible to alter the existing conditions for the practice of teacher trainees, as this involves agreements with other institutions, and which are beyond the power of the lecturer to arrange when he designs the syllabus for methodology. This happens to be my case. Our students, before they study methodology, have only been on a short visit to schools where they have learnt school organization and have been able to observe some classroom teaching. They have the opportunity to do some real teaching once they have finished the course on methodology. So, the subject is 
sandwiched between two practice periods, and there is no possibility of any teaching practice while they are studying methodology. This may not present a problem if theoretical teaching is our only concern, but it renders alternating lectures with teaching practice impossible. Their teaching practice is completely detached of their learning of methodology and on some occasions it becomes quite disconnected, since the schools they practice in have been selected by the Ministry of Education without our having had any say on how English is taught there. So they do their teaching practice in ordinary schools, not in a special type of demonstration schools, with specially appointed teachers. I have had direct experience of the result of such procedure when visiting students who were giving their practice classes. I saw them teaching in imitation of the English teacher in that school with a complete dependence from the textbook, or reverting to the type of teaching they had endured in the past. One conclusion I drew was that their methodology course (in which they had been examined) had had no influence whatsoever on their praxis. ${ }^{1}$

It confirmed my belief that, instead of limiting the transfer of instruction to the traditional type of lecture, which is eventually followed by a repetition of the contents by the student in writing, it was a better procedure to sequence theoretical explanations with practice. As I said before, this is not possible in the present system, so another solution had to be provided.

In an attempt to avoid this situation I tried to link the practice period with methodology asking them to write a paper during their teaching practice, (a teaching diary, lesson plans, etc.). However, this was not enough to render their theoretical knowledge active, for in some cases the objectives stated at the beginning of the paper were contradicted by the procedures they said they had been using.

This proved that most of my teaching had been almost completely ineffectual and made me wonder why it had to be so and try to find an answer. I considered two possible reasons:

A. This type of learning, which is so useless because it is quickly forgotten, and is unrelated to the practical side of teaching, could be explained by Ausubel's cognitive learning theory. He separates rote and meaningful learning. Rote learning does not allow the establishment of a meaningful relationship and it promotes the mental storage of new information that bears little or no association with other existing cognitive structures. In order to produce meaningful learning it is necessary to relate new material to relevant existing items in cognitive structures. It is then taken up into a more inclusive conceptual system and this will stay in long-term memory. My students' learning would come under rote learning.

B. The lack of transfer of what they had learnt to their teaching practice might lie in their attitude towards teaching. It has been proved by current research that attitudes are essential for learning, and, subsequently, they can be even more important in learning how to teach. ${ }^{2}$ Attitudes, although they have a cognitive component, condition the perception of reality and provoke certain reactions, like rejection of schemata contrary to the beliefs the subject has.

So in order to cope with the first problem the students had to learn in a more efficient mode, in such a way that learning would not only be retained but the knowledge acquired would be related to practical experience, ready to be used when it 
became relevant. In other words, I had to try making the process of learning more meaningful.

The way out of the second problem is an obvious one: the attitude had to be altered. This is what Martha C. Pennington advises:

Unless teachers from the outset of training have the proper attitudes or frame of reference within which to receive new ideas, work on methodology will have little effect on their actual teaching behaviour. («Faculty Development»94)

The possible solution to both problems, establishing appropriate links between related areas of knowledge and modifying attitudes, might lie in providing the students with the necessary frame of reference through introspection, which could be produced by means of awareness-raising activities.

Awareness-raising activities are intended to help the students to develop their understanding of the point in question through reflection and evaluation of all the possible issues. They can be designed to make the students think about the actual requirements of the language learning process. This would enable them to appreciate the range of difficulties the learner faces when he tries to overcome learning problems. These activities can also be used when alternative classroom tectiniques and their respective results are being considered. Although they supplement the understanding of theory, these activities cannot be regarded as part of the theoretical learning which a teacher needs. They must be considered as part of the practical aspect which is also necessary, and in fact they prepare the student for his actual teaching practice. This is how Rod Ellis views it:

Teacher preparation practices, in the first instance, can be divided into those that are experiential and those that raise awareness. Experiential practices involve the student teacher in actual teaching. ... Awareness-raising practices are intended to develop the student teacher's conscious understanding of the principles underlying second language teaching and/or the practical techniques that teachers can use in different kinds of lessons. (26)

He gives a list of the ways of providing data for this type of activities: video or audio recordings of actual lessons, transcripts of lessons, classroom teaching, peer teaching, microteaching, readings, textbook or teaching materials, lesson plans or outlines, case studies and samples of students' written work.

In my experience it is possible to devise awareness-raising activities related to theoretical and practical aspects of methodology.

If, for instance, the knowledge of cognitive theory is considered necessary for the future teachers, instead of starting with a description of the theory it is more worthwhile to make the students aware of their own practice of the three main types of strategies: metacognitive, cognitive, and social and affective strategies.

Through the use of retrospective and think-aloud interviews, questionnaires, checklists and observations students are made to discover the strategies used when performing first language problem-solving tasks or receptive or productive language tasks in English. In the case of their first language, once they have realized the type of 
strategy used, a similar task is proposed in English so that they can observe how to transfer the strategies used previously.

After they have had what may be called some first hand experience, the theoretical explanations, which take place immediately afterwards, can be understood better, because a more significant context has been defined.

Different methods and approaches to teaching can be dealt with in a similar way. Instead of offering the students a description they can either watch a video tape or read the transcripts of a lesson taught according to different methods. Guided observation can be followed by analysis and discussion. Exposition of the different methods should then be more comprehensible.

More practical issues can be also considered thus. Students may be asked to examine tasks or exercises so that they can see what they imply for classroom practice. They can compare lesson plans and outlines, or they may be asked to complete unfinished ones.

There are some problems which must be examined before the students enter a real classroom as teachers. The non-native English teacher must practice teacher speech, especially some aspects like eliciting pupils' speech, encoding questions in a wide range of forms, confirmation checks, clarification requests, and in general modifying conversation to be comprehensible to his pupils. It is true that the native English teacher would also have to practice teacher speech, like differentiating the role of display and referential questions, but some other aspects come more naturally to him, like adjusting and tuning their output to suit non-natives. In any case it is important for the student teacher, first, to realize that he is going to need a particular type of discourse, and then to practice it. It can be done through peer teaching, for example.

This is an attempt to overcome some of the shortcomings that the present education system imposes on us. However, an ideal situation in which the student teacher developed awareness through teaching practice backed up by simultaneous education does not seem possible in the near future.

\section{Notes}

1. This does not seem to be an isolated phenomenon, as it was one of the points of the general discussion in the Seminar for the Selection and Professional Development of Trainers for Initial Teacher Trainer, organized by the Council of Europe in Strasbourg which took place on 27-28 March 1990: «New teachers appeared to find it hard to apply in the classroom what they had leaned in training. When faced with a problem, they tended to reproduce patterns of behaviour assimilated during their own schooling, modelled on that of their own past teachers. Moreover, they had difficulty in relating the didactic and methodological skills they had learned to their knowledge of the subject matter» (Secretariat Report 6). This point was considered so important that it was suggested that «a study might be devoted to the problem of why teachers reverted to teaching models they had assimilated during their own schooling rather than applied those learned during their training» (14).

2. "There is general agreement that preparation for language teaching requires certain knowledge, skills and attitudes» (Pennington «Faculty Development» 92). 


\section{Works Cited}

Council of Europe. Secretariat Report. Strasbourg, 27-28 March 1990.

Ellis, Rod. «Activities and Procedures for Teacher Preparation.» Second Language Teacher Education. Eds. Jack C. Richards and David Nunan. New York: Cambridge UP, 1990.

Pennington, Martha $\mathrm{C}$. «A Profesional Development Focus for the Language Teaching Practicum.» Second Language Teacher Education. Eds. Jack C. Richards and David Nunan. New York: Cambridge UP, 1990.

. «Faculty Development for Language Programs.» The Second Language Curriculum. Ed. Robert Keith Johnson. Cambridge: Cambridge UP, 1989.

Richards, Jack C. «The Dilemma of Teacher Education in Second Language Teaching.» Second Language Teaching Education. Eds. Jack C. Richards and David Nunan. New York: Cambridge UP, 1990.

Widdowson, H. G. Aspects of Language Teaching. Hong Kong: Oxford UP, 1990. 